\title{
Safety and efficacy of subcutaneous tanezumab in patients with knee or hip osteoarthritis
}

This article was published in the following Dove Press journal:

Journal of Pain Research

\author{
Charles Birbara' \\ Eugene J Dabezies JR ${ }^{2}$ \\ Aimee M Burr ${ }^{3}$ \\ Robert J Fountaine ${ }^{3}$ \\ Michael D Smith ${ }^{3}$ \\ Mark T Brown ${ }^{3}$ \\ Christine R West ${ }^{3}$ \\ Rosalin H Arends ${ }^{3}$ \\ Kenneth M Verburg ${ }^{3}$ \\ 'Department of Medicine, University \\ of Massachusetts School of Medicine, \\ Worcester, MA, ${ }^{2}$ Pensacola Research \\ Consultants, Pensacola, FL, ${ }^{3}$ Clinical \\ Development and Operations \\ Business Unit, Pfizer Inc., Groton, CT, \\ USA
}

Correspondence: Mark T Brown Clinical Development and Operations Business Unit, Pfizer Inc., MS8260-2210, 445 Eastern Point Road, Groton, CT 06340, USA

Tel +l 8604055194

Fax +l 8606867578

Email mark.t.brown@pfizer.com
Background/objective: The objective of this study was to investigate the safety and efficacy of subcutaneous (SC) and intravenous (IV) tanezumab administration in osteoarthritis (OA) patients. Materials and methods: Study 1027 (NCT01089725), a placebo-controlled trial, evaluated the efficacy of SC tanezumab (ie, 2.5, 5 , and $10 \mathrm{mg}$ ) and the therapeutic equivalence of $10 \mathrm{mg}$ tanezumab given subcutaneously versus intravenously every 8 weeks in the symptomatic treatment of OA. Coprimary endpoints were: change from baseline in Western Ontario and McMaster Universities Osteoarthritis index (WOMAC) Pain and Physical Function indices, and Patient's Global Assessment (PGA) of OA. Study 1043 (NCT00994890) was a long-term, noncontrolled safety study of tanezumab (ie, $2.5,5$, and $10 \mathrm{mg}$ ) subcutaneously administered every 8 weeks. Both studies were discontinued prematurely due to a US Food and Drug Administration partial clinical hold.

Results: Due to the clinical hold, Study 1027 was underpowered, and no statistical analyses were performed. Mean (standard error [SE]) change from baseline to week 8 in WOMAC Pain in tanezumab groups ranged from $-3.59(0.26)$ to $-3.89(0.32)$, versus $-2.74(0.25)$ with placebo. Mean (SE) change from baseline to week 8 in WOMAC Physical Function ranged from $-3.13(0.25)$ to $-3.51(0.28)$ with tanezumab and was $-2.26(0.24)$ with placebo. PGA mean (SE) change from baseline to week 8 ranged from $-0.90(0.11)$ to $-1.08(0.12)$ with tanezumab and was $-0.78(0.10)$ with placebo. Similar effectiveness was associated with tanezumab in Study 1043 . Few patients in either study $(1.4 \%-5.2 \%)$ discontinued due to adverse events. Five patients required total joint replacements in Study 1027 (placebo, $n=2$ [2.8\%]; tanezumab 2.5 $\mathrm{mg}, \mathrm{n}=3$ [4.1\%]) and 34 patients in Study 1043 (tanezumab $2.5 \mathrm{mg}, \mathrm{n}=11$ [4.8\%]; tanezumab $5 \mathrm{mg}, \mathrm{n}=8$ [3.6\%]; tanezumab $10 \mathrm{mg}, \mathrm{n}=15$ [6.6\%]).

Conclusion: Preliminary results show similar efficacy and safety for both SC and IV administration of tanezumab based on the direct comparisons reported here and indirect comparisons with published results, confirming pharmacokinetic/pharmacodynamic modeling predictions.

Keywords: tanezumab, subcutaneous, osteoarthritis, efficacy, safety

\section{Plain language summary}

Tanezumab is in development for the treatment of chronic pain conditions. While tanezumab has been administered via intravenous (IV) injection in most clinical studies performed to date, subcutaneous (SC) administration is more convenient and therefore preferred. Therefore, in order to determine whether SC tanezumab is also efficacious in the symptomatic treatment of osteoarthritis (OA) pain, two clinical trials examined the efficacy and safety of tanezumab administered by SC injection, as well as the therapeutic equivalence of $10 \mathrm{mg}$ SC tanezumab versus $10 \mathrm{mg}$ IV injection. In both the studies, all tanezumab doses were associated with similar 
improvements in pain, function, and patient's overall global assessment of OA. SC tanezumab had a favorable safety profile in both the studies. These studies provide preliminary evidence that the efficacy and safety of SC tanezumab is similar to that of IV administration.

\section{Introduction}

Nerve growth factor (NGF) is a key modulator of pain signaling, ${ }^{1}$ and chronic pain is often associated with increased NGF. ${ }^{1-4}$ Tanezumab, a humanized monoclonal antibody, tightly binds NGF with high selectivity and specificity, ${ }^{2,5}$ thereby inhibiting NGF binding to its receptors (tropomyosin receptor kinase A [high-affinity receptor] and p75 [lowaffinity receptor]). ${ }^{4}$ In clinical studies of osteoarthritis (OA) pain, tanezumab produced significant, clinically meaningful improvements in pain, function, and global assessments, with an acceptable safety profile. ${ }^{6-13}$

The pharmacokinetic (PK) profile of subcutaneous (SC) tanezumab is dose-linear across the $2.5-10 \mathrm{mg}$ dose range, with $\sim 70 \%$ bioavailability compared with intravenous (IV) administration across all doses. ${ }^{14}$ To determine whether the tanezumab dose needs to be adjusted when converting from IV to SC administration, simulations were performed to predict weekly pain score over time using fixed-effect population parameter estimates from $\mathrm{PK}^{14}$ and $\mathrm{PK} /$ pharmacodynamic (PD) models. ${ }^{15}$ The simulations predicted that tanezumab concentrations are maintained above the model-estimated $\mathrm{IC}_{50}$ after SC and IV administration. Although the predicted mean change from baseline to week 1 in weekly pain score was lower with SC compared with IV dosing, this difference decreased with increasing dosage. In addition, the predicted difference between tanezumab SC and IV was $<5 \%$ by week 4 , suggesting no dosing adjustment is needed when converting to $\mathrm{SC}$ administration.

In order to confirm tanezumab SC and IV administration produce similar clinical response, two clinical trials investigated the efficacy and safety of SC tanezumab in patients with moderate-to-severe OA of the knee or hip. Since PK/ PD simulations suggested that analgesia onset differed with $\mathrm{SC}$ administration, an additional objective was to determine whether the analgesia profile for SC administration was similar across doses. Pharmacokinetics and immunogenicity were also evaluated.

\section{Materials and methods}

Studies 1027 and 1043 were conducted in compliance with the Declaration of Helsinki and International Conference on Harmonisation Good Clinical Practice guidelines. Protocols and informed consent documentation were reviewed and approved by Schulman Associates Institutional Review Board (Cincinnati, OH, USA) for all sites in Study $1027^{24}$ and all but two sites in Study $1043 .{ }^{25}$ The two additional institutional review boards utilized in Study 1043 were Health Science Institutional Review Board (Columbia, MO, USA) and Grant Medical Centre Institutional Review Board (Columbus, OH, USA). Patients provided written informed consent before undergoing any procedures. Treatment was discontinued on June 23, 2010, following a partial clinical hold placed by the US Food and Drug Administration (FDA) due to adverse events related to joint safety. ${ }^{16}$

\section{Study 1027}

Study $1027^{24}$ was a randomized, double-blind, double-dummy, placebo-controlled, multicenter, parallel-group trial designed to evaluate the efficacy and safety of tanezumab administered subcutaneously every 8 weeks in patients with knee OA (ClinicalTrials.gov identifier: NCT01089725; Figure 1A). The primary objectives were to demonstrate the efficacy of tanezumab SC administration versus placebo and therapeutic equivalence of tanezumab $10 \mathrm{mg} \mathrm{SC}$ and IV administration.

\section{Study population}

Patients in Study $1027^{24}$ were aged $\geq 18$ years with a diagnosis of OA of the knee based on the American College of Rheumatology criteria and radiographic confirmation (Kellgren-Lawrence X-ray grade $\geq 2)^{17-19}$ and Western Ontario and McMaster Universities Osteoarthritis Index (WOMAC) Pain score $\geq 4$ at screening and $\geq 5$ at baseline (on a 0-10 numeric rating scale [NRS]) in the index knee. Patients regularly taking pain medications ( $\geq 4$ days per week) during the month prior to screening had to have an increase of $\geq 1$ point in WOMAC Pain score between screening and baseline. Patients were also required to have WOMAC Physical Function score $\geq 4(0-10$ NRS) in the index knee; Patient's Global Assessment (PGA) of OA of "fair," "poor," or "very poor" at baseline; and $\geq 1$ of the following: unwilling or unable to take nonopiate pain medications (eg, nonsteroidal anti-inflammatory drugs [NSAIDs]), inadequate pain relief with nonopiate pain medications, or candidates for seeking invasive interventions (ie, intra-articular injections, knee arthroplasty, or knee replacement surgery).

Key exclusion criteria for Study 1027 were similar to previous tanezumab studies. ${ }^{67}$ They included pregnancy, nursing, or intent to become pregnant during the study; body mass index $>39 \mathrm{~kg} / \mathrm{m}^{2}$; history of joint disease or recent trauma to the index knee; significant incapacitation, fibromyalgia, or regional pain caused by lumbosacral radiculopathy; 

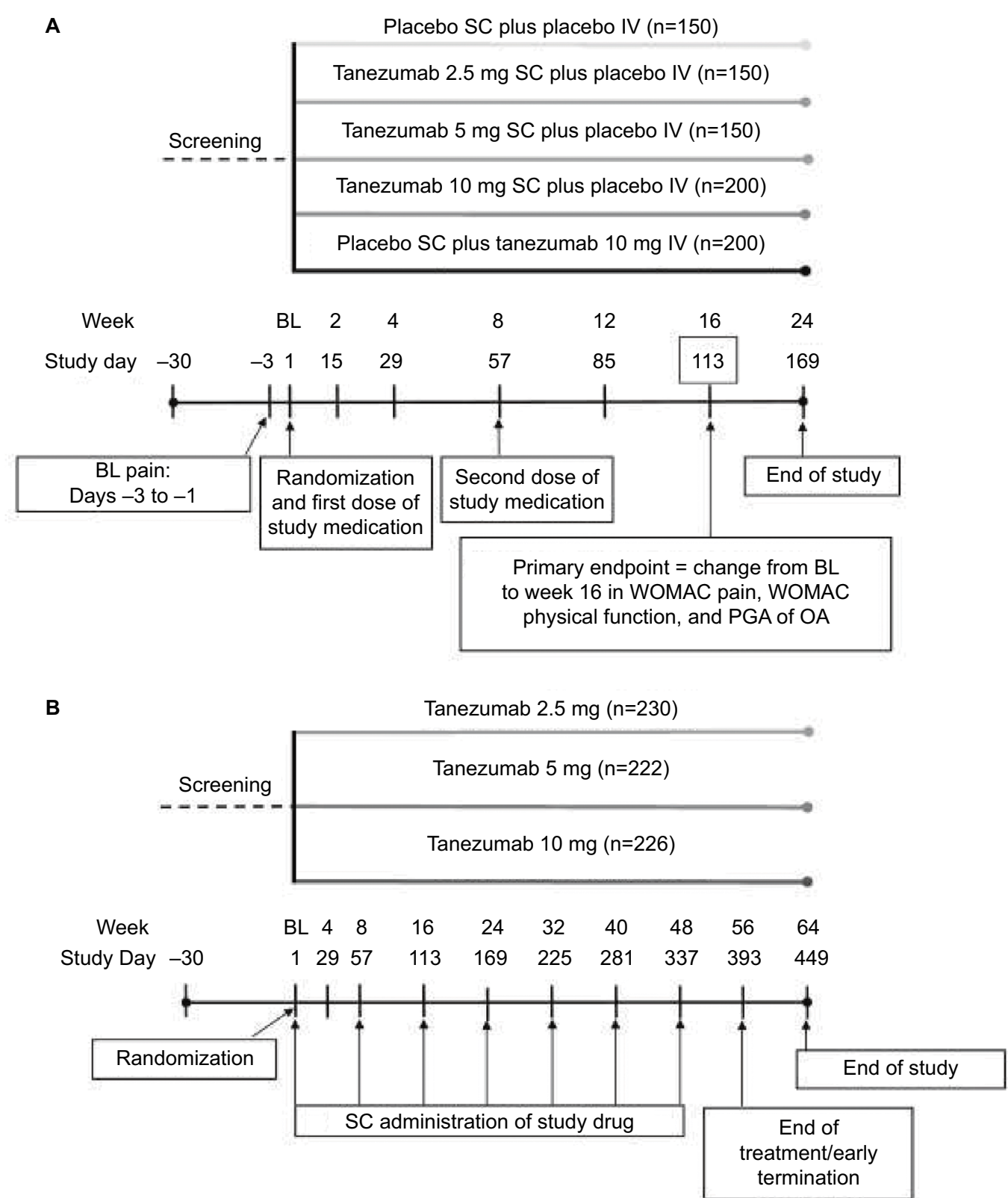

Figure I Study design. (A) Study $1027^{24}$ and (B) Study $1043 .^{25}$

Abbreviations: BL, baseline; IV, intravenous; OA, osteoarthritis; PGA, Patient's Global Assessment; SC, subcutaneous; WOMAC, Western Ontario and McMaster Universities Osteoarthritis Index.

significant cardiac, neurologic, or psychiatric conditions; planned surgery during the study; or previous exposure to exogenous NGF or NGF antibody.

\section{Study design and treatments}

Study 1027 consisted of a screening period (up to 30 days prior to randomization), including washout (minimum 2-day washout, if required), initial pain assessment (3 days prior to randomization/baseline), treatment lasting 16 weeks, and follow-up of 8 weeks (Figure 1A). Patients were randomized in a 3:3:3:4:4 ratio to placebo SC plus placebo IV, tanezumab
$2.5 \mathrm{mg}$ SC plus placebo IV, tanezumab $5 \mathrm{mg}$ SC plus placebo $\mathrm{IV}$, tanezumab $10 \mathrm{mg}$ SC plus placebo IV, and tanezumab 10 mg IV plus placebo SC administered at 8-week intervals.

Tanezumab or corresponding placebo was administered by IV infusion preferably in the antecubital fossa. All patients received $5 \mathrm{~mL}$ of study medication $(1 \mathrm{~mL}$ of study medication plus $4 \mathrm{~mL}$ of sodium chloride injection, United States Pharmacopeia [USP]) administered over 5 minutes without infusion pump (slow IV push) followed with an IV flush of $5 \mathrm{~mL}$ of sodium chloride for injection, USP. The SC injections consisted of $1 \mathrm{~mL}$ of study medication (tanezumab or 
corresponding placebo) injected in the abdomen or anterior aspect of the thigh.

\section{Efficacy}

Efficacy was assessed as a change from baseline to week 16 in three coprimary endpoints: WOMAC Pain, WOMAC Physical Function, and PGA of OA. WOMAC scores were recorded on an 11-point NRS (higher scores indicated greater pain or functional impairment); PGA was recorded on a 5 -point scale ( 1 =very good, 5 =very poor). ${ }^{20,21}$ Secondary endpoints included the percentage of patients with $\geq 30 \%$, $\geq 50 \%, \geq 70 \%$, and $\geq 90 \%$ improvements from baseline in WOMAC Pain and the percentage of patients considered responders using the Outcome Measures in Rheumatology Arthritis Clinical Trials-Osteoarthritis Research Society International (OMERACT-OARSI) responder index (defined as a $\geq 50 \%$ change and $\geq 2$-point absolute change on either WOMAC Pain or WOMAC Physical Function subscales or $\geq 20 \%$ change and $\geq 1$-point absolute change for at least two of the three coprimary endpoints). ${ }^{22}$

\section{Statistical analysis}

Efficacy and safety analyses for Study 1027 were based on the intent-to-treat (ITT) population (all patients randomized and treated with at least one SC or IV dose). For the three coprimary endpoints, the number and percentage of patients in each response category were summarized by treatment and time on an observed case basis using last observation carried forward imputation for missing data. The total planned sample size was 850 patients.

In order to determine whether tanezumab was superior to placebo, a sample size of 150 patients per treatment was required to provide $90 \%$ power to achieve statistical significance at the 5\% two-sided level for comparisons of tanezumab 5 and $10 \mathrm{mg}$ SC versus placebo over all three coprimary endpoints. This sample size would yield $\sim 80 \%$ power to achieve statistical significance for all three tanezumab SC doses versus placebo comparisons over all three coprimary endpoints. In order to establish therapeutic equivalence of tanezumab $10 \mathrm{mg} \mathrm{SC}$ and IV over all three coprimary endpoints, a sample size of 200 patients in the tanezumab $10 \mathrm{mg}$ SC and tanezumab $10 \mathrm{mg}$ IV groups was needed to provide $\sim 90 \%$ power. The margins against which the $90 \%$ confidence limits were to be compared were set to \pm 1.0 for WOMAC Pain and Physical Function indices and \pm 0.4 for PGA of OA. In addition, therapeutic equivalence required point estimates for the difference in least squares mean to fall within one-half of the corresponding confidence limit bounds. Therefore, the total planned sample size to meet both the primary objectives was 850 patients.

Since Study 1027 was not fully enrolled due to the partial clinical hold, the sample size was insufficient to meet study objectives; therefore, no statistical hypothesis testing was performed. Changes to planned analyses were made prior to unblinding of the study.

\section{Study 1043}

Study $1043^{25}$ was a randomized, double-blind, parallel-group, multicenter, long-term safety trial of tanezumab $2.5,5$, and $10 \mathrm{mg} \mathrm{SC}$ in patients with moderate-to-severe knee or hip OA (ClinicalTrials.gov identifier: NCT00994890; Figure 1B).

\section{Study population}

Inclusion criteria were identical to Study 1027 except that patients with OA of the hip were eligible to participate in the study, there were no requirements regarding intolerance or inability to take other analgesics, WOMAC Pain score $\geq 4$ (instead of $\geq 5$ ) at baseline, and patients regularly (average $\geq 4$ days per week) used an opioid or nonopioid analgesic for OA pain.

Key exclusion criteria for Study 1043 were largely similar to Study 1027 and included pregnancy, nursing, or intent to become pregnant during the study; body mass index $>39 \mathrm{~kg} / \mathrm{m}^{2}$; history of joint disease or recent trauma to the index knee or hip; significant incapacitation, fibromyalgia, or regional pain caused by lumbosacral radiculopathy; significant cardiac, neurologic, or psychiatric conditions; planned surgery during the study; or previous exposure to exogenous NGF or NGF antibody.

\section{Study design and treatments}

Patients in Study 1043 were randomized in equal allocation to SC tanezumab $2.5,5$, or $10 \mathrm{mg}$ administered at 8 -week intervals (seven doses total) for up to $\sim 1$ year; placebo treatment and tanezumab IV administration were not included in this study. Approved prescription analgesics, over-the-counter analgesics, or muscle relaxants as concomitant analgesic medications for OA were permitted. Tanezumab injections $(1 \mathrm{~mL})$ were administered subcutaneously in the abdomen or anterior aspect of the thigh using the same formulation as Study 1027.

\section{Efficacy}

Efficacy was assessed as a change from baseline to various time points in WOMAC Pain; WOMAC Physical Function; PGA of OA; the percentage of patients with $\geq 30 \%, \geq 50 \%$, 
$\geq 70 \%$, and $\geq 90 \%$ improvements in WOMAC Pain; and the percentage of OMERACT-OARSI responders.

\section{Statistical analysis}

Efficacy and safety were assessed in the ITT population. There were no statistical comparisons among groups. Last observation carried forward imputation was used for missing data for efficacy analyses. A sample size of 200 patients per group (600 patients in total) provided $95 \%$ probability of at least one patient with an individual adverse event where the true adverse event rate was $\sim 1.5 \%$.

\section{Both studies \\ Safety}

Safety assessments in both the studies included adverse event documentation, vital signs, physical and neurologic examinations, 12-lead electrocardiogram, injection site assessment, and laboratory test results. Injection and infusion site assessments were conducted 1 hour postdose and at follow-up assessments. If an injection/infusion site reaction was observed, further assessments were carried out to monitor resolution. Study investigators performed standardized neurologic examinations at each clinic visit. If a neurologic adverse event was reported or clinically significant change was noted on examination, the patient was referred to a neurologist for further evaluation. Following the implementation of the partial clinical hold, a blinded external adjudication committee, consisting of orthopedic surgeons, rheumatologists, and an orthopedic pathologist, convened to review adverse events reported as total joint replacement (TJR) and all adverse events initially reported as osteonecrosis.

Blood samples were collected at baseline (Day 1) in both the studies; at weeks 8, 16, and 24 (or early termination; Study 1027); and weeks 8, 24, and 40 (or early termination; Study 1043) for the assessment of antidrug antibodies (ADAs). Serum ADA analysis followed a tiered approach using screening, confirmation, and titer/quantitation in a validated semi-quantitative enzyme-linked immunosorbent Fab assay (ELISA; ICON Development Solutions LLC, Whitesboro, NY, USA). ADA-positive samples were analyzed in a neutralizing antibody (NAb) binding assay to characterize the response. Samples were considered positive if the titer was at or above the assay limit of detection ( $\log _{2}$ of the minimum required 20 -fold dilution [4.32]).

\section{Pharmacokinetics}

Blood samples (3-4 mL) were collected for tanezumab PK assessments at baseline (predose; both studies); weeks 1, 2,
4, 8 (predose), 12, 16, and 24 (or early termination) in Study 1027; and at weeks 2, 8 (predose), 24 (predose), 40 (predose), or early termination in Study 1043. Plasma samples were analyzed by using a validated, sensitive, and specific ELISA (ICON Development Solutions).

\section{Results \\ Study 1027}

Overall, 379 patients (45\% of the planned population) were randomized, treated with study medication, and comprised the ITT population (Figure 2A). Baseline characteristics were similar across treatments (Table 1). Due to $<10 \%$ of patients receiving a second dose at week 8 , efficacy results are described for change from baseline to week 8 only. Mean duration of treatment (108.4-113.5 days) was similar across treatment groups.

\section{Efficacy}

Mean (standard error [SE]) change from baseline to week 8 in WOMAC Pain score in the tanezumab groups ranged from $-3.59(0.26)$ to $-3.89(0.32)$; the corresponding change with placebo was $-2.74(0.25)$ (Figure 3A). Mean (SE) change from baseline to week 8 in WOMAC Physical Function score ranged from $-3.13(0.25)$ to $-3.51(0.28)$ with tanezumab and $-2.26(0.24)$ with placebo (Figure 3B). For PGA of OA score, mean (SE) change from baseline to week 8 was -0.90 $(0.11)$ to $-1.08(0.12)$ with tanezumab and $-0.78(0.10)$ with placebo (Figure 3C). Inspection of the efficacy-time curves indicated onset and duration of analgesia with all SC doses were similar to the $10 \mathrm{mg}$ IV dose over the 8-week dosing interval.

The percentage of patients with $\geq 30 \%, \geq 50 \%, \geq 70 \%$, and $\geq 90 \%$ reductions in WOMAC Pain score at week 8 was greater in all tanezumab groups versus placebo (Figure 3D). These differences were more pronounced at the $\geq 70 \%$ and $\geq 90 \%$ levels. The percentage of patients with OMERACTOARSI response at week 8 was greater with tanezumab dosing than with placebo (Figure 3E).

\section{Safety}

Overall, the incidence of all-causality adverse events in Study 1027 was highest with tanezumab $10 \mathrm{mg}$ IV and placebo versus tanezumab 2.5 and $5 \mathrm{mg}$ SC (Table 2). No deaths occurred. Five treatment-emergent serious adverse events were reported: two each in the tanezumab $2.5 \mathrm{mg} \mathrm{SC}$ $(2.7 \%)$ and placebo groups $(2.8 \%)$ and one $(1.2 \%)$ in the tanezumab $10 \mathrm{mg}$ IV group (Table 2). The most frequent adverse events ( $\geq 5 \%$ of patients in any group) included 
A

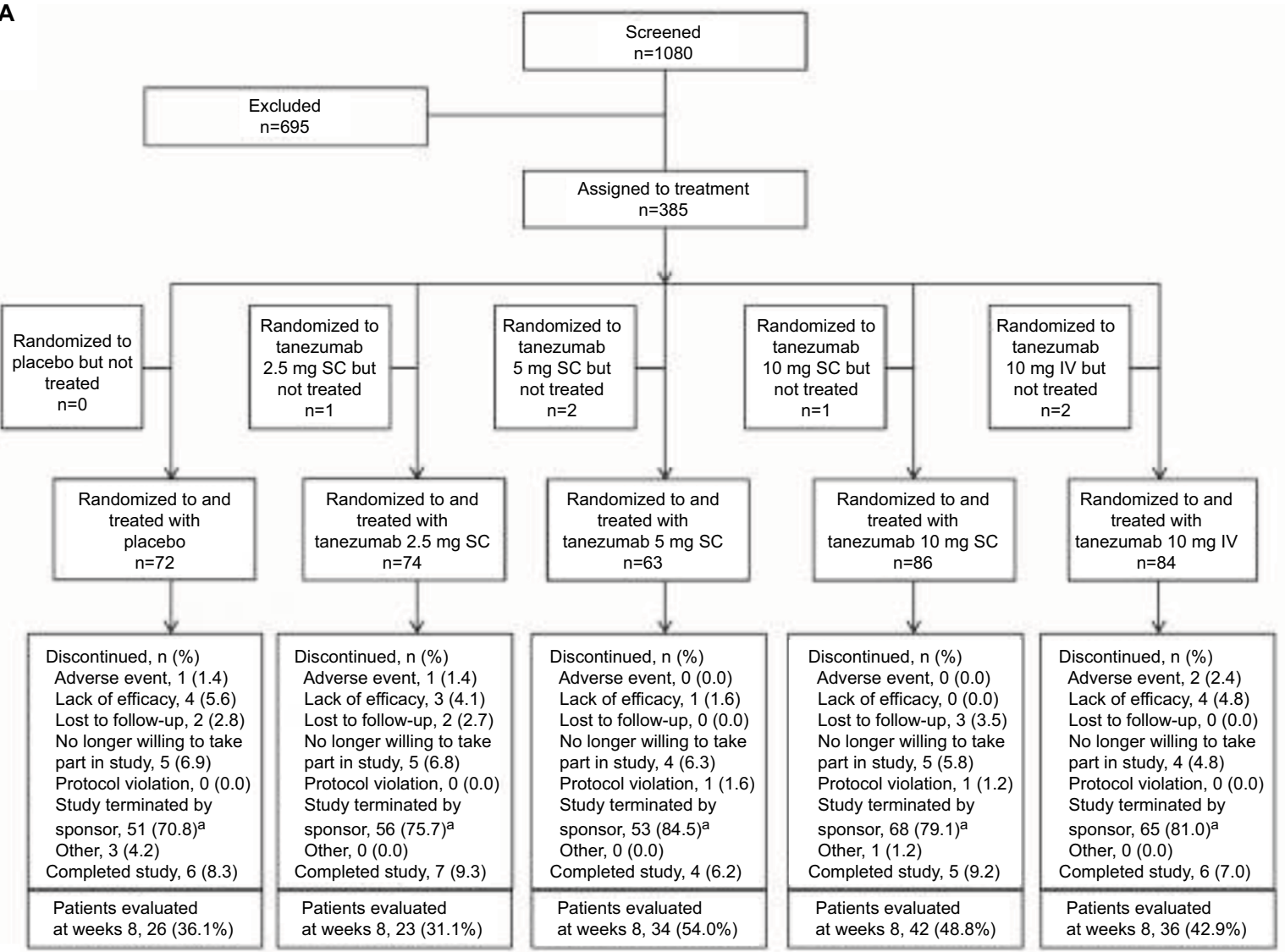

B

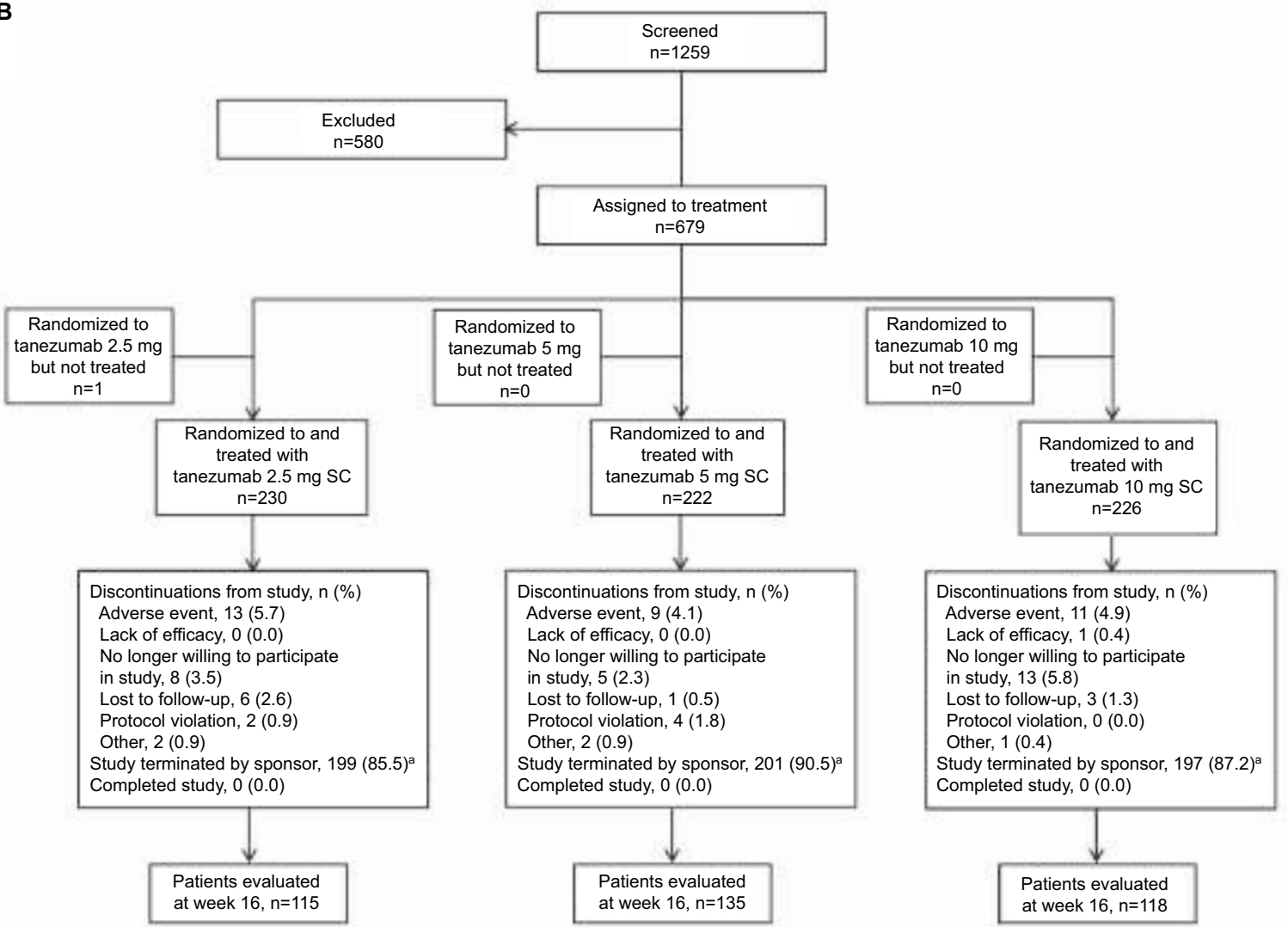

Figure 2 Patient disposition in (A) Study $1027^{24}$ and (B) Study 1043.25

Note: ${ }^{\mathrm{T} T e r m i n a t i o n}$ due to partial clinical hold placed by US FDA.

Abbreviations: FDA, Food and Drug Administration; IV, intravenous; SC, subcutaneous. 
Table I Patient demographic characteristics, duration of disease, and doses of study medication administered

\begin{tabular}{|c|c|c|c|c|c|c|c|c|}
\hline & \multicolumn{5}{|l|}{ Study $1027^{24}$} & \multirow{2}{*}{\multicolumn{3}{|c|}{$\begin{array}{l}\text { Study } 1043^{25} \\
\text { Tanezumab }\end{array}$}} \\
\hline & \multirow{2}{*}{$\begin{array}{l}\text { Placebo } \\
n=72\end{array}$} & \multicolumn{4}{|l|}{ Tanezumab } & & & \\
\hline & & $\begin{array}{l}2.5 \mathrm{mg} \mathrm{SC} \\
(\mathrm{n}=74)\end{array}$ & $\begin{array}{l}5 \mathrm{mg} \mathrm{SC} \\
(\mathrm{n}=63)\end{array}$ & $\begin{array}{l}10 \mathrm{mg} \mathrm{SC} \\
(\mathrm{n}=86)\end{array}$ & $\begin{array}{l}10 \mathrm{mg} \mathrm{IV} \\
(\mathrm{n}=84)\end{array}$ & $\begin{array}{l}2.5 \mathrm{mg} \mathrm{SC} \\
(\mathrm{n}=230)\end{array}$ & $\begin{array}{l}5 \mathrm{mg} \mathrm{SC} \\
(\mathrm{n}=222)\end{array}$ & $\begin{array}{l}10 \mathrm{mg} \mathrm{SC} \\
(\mathrm{n}=226)\end{array}$ \\
\hline \multicolumn{9}{|l|}{ Gender, n (\%) } \\
\hline Female & $47(65.3)$ & $48(64.9)$ & $36(57.1)$ & $54(62.8)$ & $48(57.1)$ & $152(66.1)$ & $157(70.7)$ & I6I (7I.2) \\
\hline $\begin{array}{l}\text { Age, mean (range), } \\
\text { years }\end{array}$ & $61.3(25-84)$ & $61.0(21-84)$ & $60.3(32-8 I)$ & $58.2(40-83)$ & $59.6(24-87)$ & $61.7(38-89)$ & $62.4(36-91)$ & $63.4(27-94)$ \\
\hline Weight, mean (SD), kg & $85.6(17.4)$ & $86.7(17.2)$ & $90.8(19.0)$ & $90.7(14.8)$ & $90.0(16.1)$ & $87.8(17.0)$ & $85.4(17.0)$ & $89.0(17.5)$ \\
\hline BMI, mean (SD), $\mathrm{kg} / \mathrm{m}^{2}$ & $30.8(5.4)$ & $30.5(4.8)$ & $31.0(4.8)$ & $31.7(4.3)$ & $30.7(4.5)$ & $30.8(4.7)$ & $30.7(5.0)$ & $31.7(4.8)$ \\
\hline \multicolumn{9}{|l|}{ Race, n (\%) } \\
\hline White & $60(83.3)$ & $60(81.1)$ & $51(81.0)$ & $73(84.9)$ & $73(86.9)$ & $197(85.7)$ & $191(86.0)$ & $193(85.4)$ \\
\hline Black & $10(13.9)$ & $9(12.2)$ & $8(12.7)$ & $10(11.6)$ & $5(6.0)$ & $25(10.9)$ & $22(9.9)$ & $29(12.8)$ \\
\hline Asian & $2(2.8)$ & $4(5.4)$ & $2(3.2)$ & $2(2.3)$ & $4(4.8)$ & $\mathrm{I}(0.4)$ & $4(1.8)$ & $3(1.3)$ \\
\hline Other & $0(0.0)$ & $\mathrm{I}(1.4)$ & $2(3.2)$ & $\mathrm{I}(\mathrm{I} .2)$ & $2(2.4)$ & $7(3.0)$ & $5(2.3)$ & $\mathrm{I}(0.4)$ \\
\hline \multicolumn{9}{|l|}{ Index joint, $n$ (\%) } \\
\hline Knee & $72(100)$ & $74(100)$ & $63(100)$ & $86(100)$ & $84(100)$ & $183(79.6)$ & $190(85.6)$ & $186(82.3)$ \\
\hline Hip & $0(0.0)$ & $0(0.0)$ & $0(0.0)$ & $0(0.0)$ & $0(0.0)$ & $47(20.4)$ & $32(14.4)$ & $40(17.7)$ \\
\hline \multicolumn{9}{|c|}{ Kellgren-Lawrence grade $\mathrm{n}(\%)$} \\
\hline 0 & $0(0.0)$ & $0(0.0)$ & $0(0.0)$ & $0(0.0)$ & $0(0.0)$ & $0(0.0)$ & $I(<I .0)$ & $0(0.0)$ \\
\hline 1 & $0(0.0)$ & $0(0.0)$ & $0(0.0)$ & $0(0.0)$ & $0(0.0)$ & $\mathrm{I}(<\mathrm{I} .0)$ & $0(0.0)$ & $0(0.0)$ \\
\hline 2 & $33(45.8)$ & $32(43.2)$ & $25(39.7)$ & $40(46.5)$ & $44(52.4)$ & $80(34.8)$ & $75(33.8)$ & $71(33.4)$ \\
\hline 3 & $26(36.1)$ & $31(41.9)$ & $31(49.2)$ & $34(39.5)$ & $32(38.1)$ & $111(48.3)$ & $102(45.9)$ & $116(51.3)$ \\
\hline 4 & $13(18.1)$ & II (14.9) & $7(11.1)$ & $12(14.0)$ & $8(9.5)$ & $38(16.5)$ & $43(19.4)$ & $39(17.3)$ \\
\hline \multicolumn{9}{|c|}{ Duration since the diagnosis of $O A$, years } \\
\hline Mean (range) & $9.6(0-5 \mathrm{I})$ & $7.3(0-4 I)$ & $9.1(0-50)$ & $8.7(0-47)$ & $8.2(0-40)$ & $8.4(0-45)$ & $8.7(0-42)$ & $7.3(0-50)$ \\
\hline \multicolumn{9}{|c|}{ Number of doses administered } \\
\hline 1 & 65 & 67 & 56 & 78 & 77 & 48 & 36 & 38 \\
\hline 2 & 7 & 7 & 7 & 8 & 7 & 99 & 89 & 103 \\
\hline 3 & 0 & 0 & 0 & 0 & 0 & 64 & 72 & 61 \\
\hline 4 & 0 & 0 & 0 & 0 & 0 & 19 & 25 & 24 \\
\hline \multicolumn{9}{|c|}{ Duration of treatment, days } \\
\hline Mean (range) & $\begin{array}{l}110.7 \\
(8-180)\end{array}$ & $\begin{array}{l}110.2 \\
(8-170)\end{array}$ & $\begin{array}{l}111.3 \\
(8-176)\end{array}$ & $\begin{array}{l}113.5 \\
(9-176)\end{array}$ & $\begin{array}{l}108.4 \\
(8-170)\end{array}$ & $\begin{array}{l}180.3 \\
(14-345)\end{array}$ & $\begin{array}{l}190.8 \\
(|5-3| 1)\end{array}$ & $\begin{array}{l}187.2 \\
(14-333)\end{array}$ \\
\hline
\end{tabular}

Abbreviations: BMI, body mass index; IV, intravenous; OA, osteoarthritis; SC, subcutaneous; SD, standard deviation.

arthralgia, paresthesia, hypoesthesia, worsening OA, headache, and joint swelling; two of these events (paresthesia and hypoesthesia) occurred only in patients receiving tanezumab. Injection site reaction incidence was generally low $(\leq 4.7 \%)$ across treatments. Most reactions were mild in severity; none were severe.

Adverse events of abnormal peripheral sensation reported in $>2 \%$ of patients in any group were paresthesia, hypoesthesia, burning sensation, and sensory disturbance (Table 2). Most patients ( $\geq 95 \%$ ) had no new or worsened abnormalities at final neurologic examination (Table 2).

No adverse events of osteonecrosis were reported by investigators. Five patients underwent TJR: two placebotreated patients and three patients receiving tanezumab 2.5 $\mathrm{mg} \mathrm{SC}$. One event reviewed by the adjudication committee was judged as normal progression of OA. The other four events were not reviewed due to lack of radiographic images.

\section{Pharmacokinetics and anti-tanezumab antibodies}

Overall, in Study 1027, PK descriptive summaries and individual profiles of tanezumab suggest that absorption and disposition of SC tanezumab were similar across doses. Tanezumab was slowly absorbed, with maximum plasma concentrations generally occurring within 1-2 weeks of the first injection (Figure 4). The increase in median peak and trough (week 8) concentrations was approximately proportional to dose. Because of the clinical hold, most patients received only a single dose following which median plasma concentrations of tanezumab declined exponentially throughout the remainder of the study period. 
A

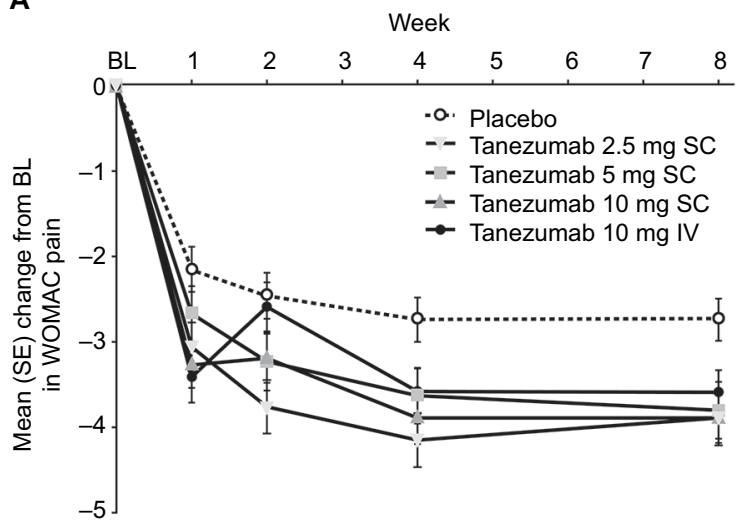

C

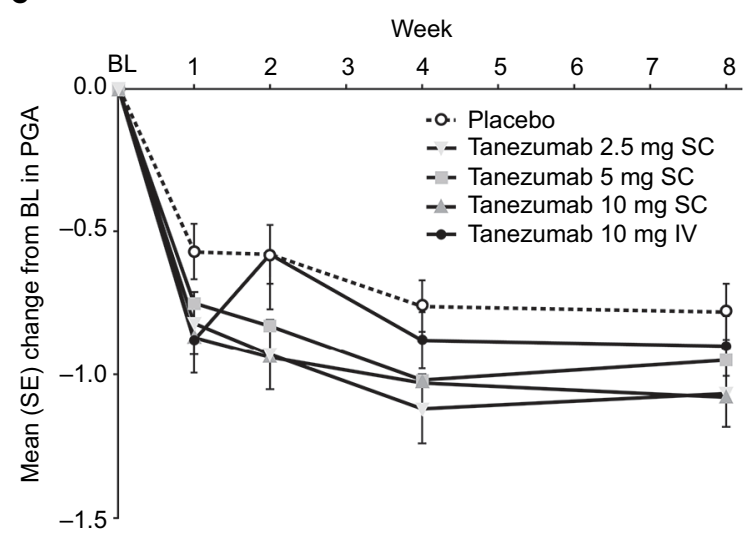

B

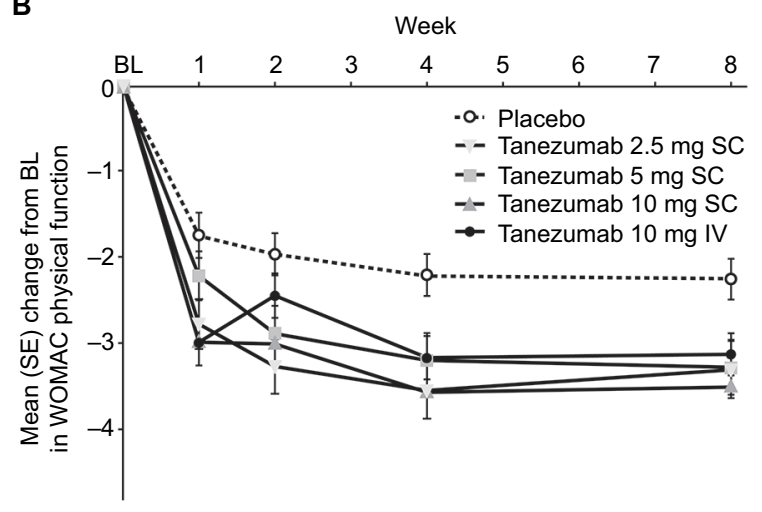

D

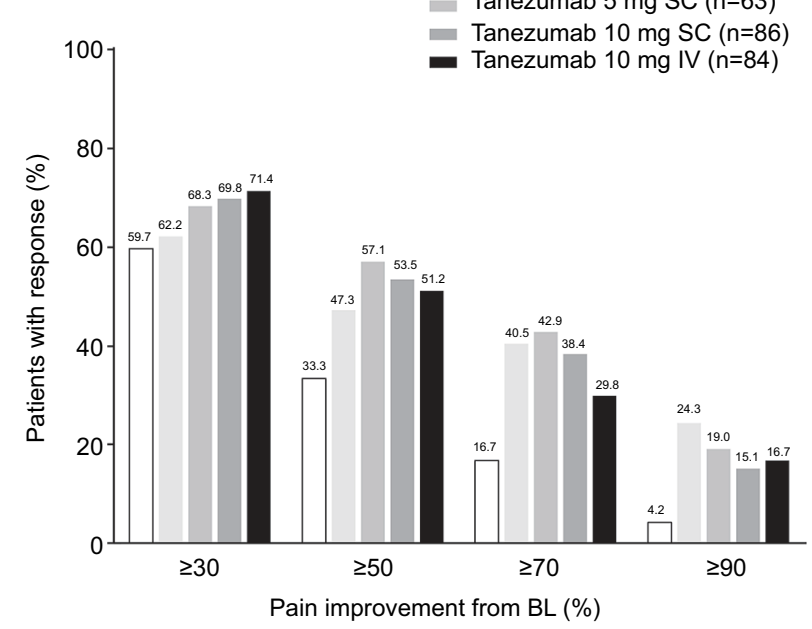

E

$\square$ Placebo ( $n=72)$

Tanezumab $2.5 \mathrm{mg} \mathrm{SC}(\mathrm{n}=74)$

- Tanezumab $5 \mathrm{mg}$ SC $(\mathrm{n}=63)$

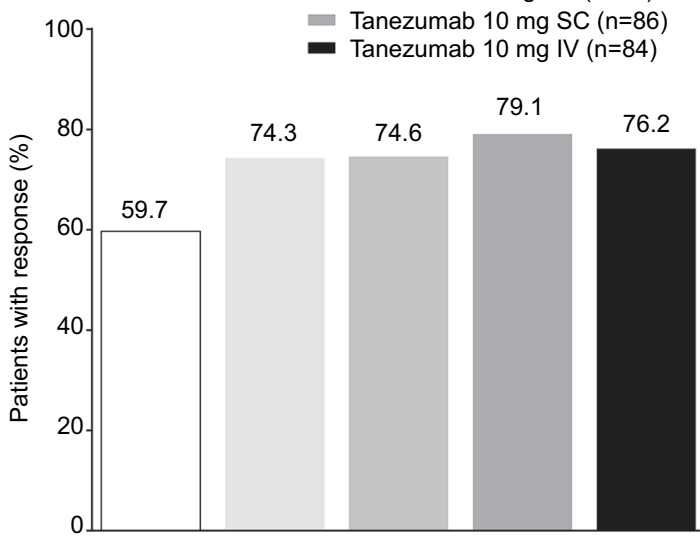

OMERACT-OARSI response at week 8

Figure 3 Study 1027:24 Mean (SE) change from baseline in (A) WOMAC Pain, (B) WOMAC Physical Function, and (C) PGA of OA; (D) percentage of patients with $\geq 30 \%$, $\geq 50 \%, \geq 70 \%$, and $\geq 90 \%$ reduction from baseline in WOMAC pain scores; and (E) OMERACT-OARSI response at week 8 (ITT, LOCF).

Abbreviations: BL, baseline; ITT, intent-to-treat; IV, intravenous; LOCF, last observation carried forward; OA, osteoarthritis; OMERACT-OARSI, Outcome Measures in Rheumatology Arthritis Clinical Trials-Osteoarthritis Research Society International; PGA, Patient's Global Assessment; SC, subcutaneous; SE, standard error; WOMAC, Western Ontario and McMaster Universities Osteoarthritis Index.

The immunogenicity profile was favorable, with only $2.3 \%$ of patients testing positive for the presence of ADA in the four tanezumab treatment groups. Among 827 serum samples screened (from 307 patients in total), 294 samples were presumptively
ADA-positive, and on further testing, only 11 samples (in seven patients) were confirmed as ADA-positive. Upon titer/quantitation analysis, nine samples had titer results $>4.32$. One patient was considered baseline positive with no increase in titer postdose, 
Table 2 Treatment-emergent adverse events (observed data) and summary of final neurologic consultations (ITT population, observed data)

\begin{tabular}{|c|c|c|c|c|c|c|c|c|}
\hline \multirow{3}{*}{$\begin{array}{l}\text { Adverse events and final neurologic } \\
\text { consultations }\end{array}$} & \multicolumn{5}{|c|}{ Study $1027^{24}$} & \multirow{2}{*}{\multicolumn{3}{|c|}{$\begin{array}{l}\text { Study } 1043^{25} \\
\text { Tanezumab }\end{array}$}} \\
\hline & \multirow{2}{*}{$\begin{array}{l}\text { Placebo } \\
(n=72)\end{array}$} & \multicolumn{4}{|l|}{ Tanezumab } & & & \\
\hline & & $\begin{array}{l}2.5 \mathrm{mg} \mathrm{SC} \\
(\mathrm{n}=74)\end{array}$ & $\begin{array}{l}5 \mathrm{mg} \mathrm{SC} \\
(\mathrm{n}=63)\end{array}$ & $\begin{array}{l}10 \mathrm{mg} \mathrm{SC} \\
(\mathrm{n}=86)\end{array}$ & $\begin{array}{l}10 \mathrm{mg} \text { IV } \\
(\mathrm{n}=84)\end{array}$ & $\begin{array}{l}2.5 \mathrm{mg} \mathrm{SC} \\
(\mathrm{n}=230)\end{array}$ & $\begin{array}{l}5 \mathrm{mg} \mathrm{SC} \\
(\mathrm{n}=222)\end{array}$ & $\begin{array}{l}10 \mathrm{mg} \mathrm{SC} \\
(n=226)\end{array}$ \\
\hline Patients with AEs & $37(5 \mathrm{I} .4)$ & $35(47.3)$ & $31(49.2)$ & $36(4 \mid .9)$ & $44(52.4)$ & $158(68.7)$ & $169(76.1)$ & $181(80.1)$ \\
\hline Patients with SAEs & $2(2.8)$ & $2(2.7)$ & $0(0.0)$ & $0(0.0)$ & $\mathrm{I}(\mathrm{I} .2)$ & $17(7.4)$ & $12(5.4)$ & $20(8.8)$ \\
\hline Patients discontinued due to $\mathrm{AEs}$ & $\mathrm{I}(\mathrm{l} .4)$ & $\mathrm{I}(\mathrm{l} .4)$ & $0(0.0)$ & $0(0.0)$ & $2(2.4)$ & $12(5.2)$ & $9(4.1)$ & II (4.9) \\
\hline \multicolumn{9}{|l|}{ AEs reported in $\geq 5 \%$ in any group ${ }^{a}$} \\
\hline Arthralgia & $4(5.6)$ & $4(5.4)$ & $7(11.1)$ & $5(5.8)$ & $5(6.0)$ & $37(16.1)$ & $30(13.5)$ & $27(11.9)$ \\
\hline Paresthesia & $0(0.0)$ & $\mathrm{I}(\mathrm{l} .4)$ & $2(3.2)$ & $6(7.0)$ & $6(7.1)$ & $13(5.7)$ & $17(7.7)$ & $25(11.1)$ \\
\hline Peripheral edema & $0(0.0)$ & $\mathrm{I}(\mathrm{l} .4)$ & $3(4.8)$ & $4(4.7)$ & $3(3.6)$ & $9(3.9)$ & $16(7.2)$ & $22(9.7)$ \\
\hline Injection site reaction & $2(2.8)$ & $2(2.7)$ & $0(0.0)$ & $4(4.7)$ & $3(3.6)$ & $19(8.3)$ & $21(9.5)$ & $20(8.8)$ \\
\hline Urinary tract infection & $0(0.0)$ & $2(2.7)$ & $0(0.0)$ & $2(2.3)$ & $0(0.0)$ & II (4.8) & $12(5.4)$ & $20(8.8)$ \\
\hline Osteoarthritis & $5(6.9)$ & $4(5.4)$ & $0(0.0)$ & $\mathrm{I}(\mathrm{I} .2)$ & $0(0.0)$ & $8(3.5)$ & $12(5.4)$ & $19(8.4)$ \\
\hline Pain in extremity & $2(2.8)$ & $\mathrm{I}(\mathrm{I} .4)$ & $3(4.8)$ & $4(4.7)$ & $3(3.6)$ & $14(6.1)$ & $12(5.4)$ & $16(7.1)$ \\
\hline Hypoesthesia & $0(0.0)$ & $2(2.7)$ & $\mathrm{I}(\mathrm{I} .6)$ & $6(7.0)$ & $2(2.4)$ & $14(6.1)$ & $6(2.7)$ & $15(6.6)$ \\
\hline Joint swelling & $4(5.6)$ & I (I.4) & $2(3.2)$ & $3(3.5)$ & $\mathrm{I}(\mathrm{I} .2)$ & $8(3.5)$ & $10(4.5)$ & $13(5.8)$ \\
\hline Fall & $0(0.0)$ & $2(2.7)$ & I (I.6) & $\mathrm{I}(\mathrm{I} .2)$ & $\mathrm{I}(\mathrm{I} .2)$ & $7(3.0)$ & $5(2.3)$ & $12(5.3)$ \\
\hline Musculoskeletal pain & $0(0.0)$ & $2(2.7)$ & $2(3.2)$ & $2(2.3)$ & $2(2.4)$ & $8(3.5)$ & $15(6.8)$ & $12(5.3)$ \\
\hline Upper respiratory tract infection & $0(0.0)$ & $2(2.7)$ & $\mathrm{I}(\mathrm{l} .6)$ & $0(0.0)$ & $2(2.4)$ & $12(5.2)$ & $9(4.1)$ & $12(5.3)$ \\
\hline Headache & $3(4.2)$ & $5(6.8)$ & $0(0.0)$ & $5(6.8)$ & $2(2.4)$ & $9(3.9)$ & $6(2.7)$ & $10(4.4)$ \\
\hline \multicolumn{9}{|c|}{ AEs of abnormal peripheral sensation in $\geq 2 \%$ in any group ${ }^{\mathrm{a}, \mathrm{b}}$} \\
\hline Paresthesia & $0(0.0)$ & $\mathrm{I}(\mathrm{l} .4)$ & $2(3.2)$ & $6(7.0)$ & $6(7.1)$ & $13(5.7)$ & $17(7.7)$ & $25(11.1)$ \\
\hline Hypoesthesia & $0(0.0)$ & $2(2.7)$ & $\mathrm{I}(\mathrm{l} .6)$ & $6(7.0)$ & $2(2.4)$ & $14(6.1)$ & $6(2.7)$ & $15(6.6)$ \\
\hline Burning sensation & $0(0.0)$ & $\mathrm{I}(\mathrm{l} .4)$ & $2(3.2)$ & $0(0.0)$ & $2(2.4)$ & $\mathrm{I}(0.4)$ & $5(2.3)$ & $2(0.9)$ \\
\hline Sensory disturbance & $0(0.0)$ & $0(0.0)$ & $0(0.0)$ & $2(2.3)$ & $0(0.0)$ & $0(0.0)$ & $0(0.0)$ & $2(0.9)$ \\
\hline \multicolumn{9}{|l|}{ Final neurologic consultation categorization ${ }^{c}$} \\
\hline Patients referred for consultation & $0(0.0)$ & $3(4.1)$ & $4(6.3)$ & $8(9.3)$ & $7(8.3)$ & $29(12.6)$ & $34(15.3)$ & $45(19.9)$ \\
\hline $\begin{array}{l}\text { Suggestive of new or worsened peripheral } \\
\text { neuropathy based on symptoms, signs, or } \\
\text { diagnostic tests }\end{array}$ & $0(0.0)$ & $2(2.7)$ & $2(3.2)$ & $6(7.0)$ & $3(3.6)$ & II (4.8) & $10(4.5)$ & $17(7.5)$ \\
\hline Not suggestive of neuropathy & $0(0.0)$ & $0(0.0)$ & $0(0.0)$ & $\mathrm{I}(\mathrm{I} .2)$ & $\mathrm{I}(\mathrm{I} .2)$ & $5(2.2)$ & $6(2.7)$ & $7(3.1)$ \\
\hline $\begin{array}{l}\text { Neurologic signs or symptoms suggestive } \\
\text { of a pre-existing neuropathy }\end{array}$ & $0(0.0)$ & $\mathrm{I}(\mathrm{l} .4)$ & $\mathrm{I}(\mathrm{l} .6)$ & $\mathrm{I}(\mathrm{I} .2)$ & $\mathrm{I}(\mathrm{I} .2)$ & $8(3.5)$ & $6(2.7)$ & II (4.9) \\
\hline No neurologic symptoms or signs & $0(0.0)$ & $0(0.0)$ & $\mathrm{I}(\mathrm{l} .6)$ & $0(0.0)$ & $2(2.4)$ & $5(2.2)$ & $12(5.4)$ & $10(4.4)$ \\
\hline
\end{tabular}

Notes: All values presented as $n(\%)$ unless otherwise noted. aPresentation order based on incidence in Study $1043^{25}$ tanezumab 10 mg SC group. ${ }^{b} \mathrm{AEs}$ of abnormal peripheral sensation included allodynia, axonal neuropathy, burning sensation, decreased vibratory sense, demyelinating polyneuropathy, dysesthesia, formication, hyperesthesia, hyperpathia, hypoesthesia, hypoesthesia facial, hypoesthesia oral, intercostal neuralgia, neuralgia, neuritis, neuropathy peripheral, paresthesia, paresthesia oral, peripheral sensorimotor neuropathy, peripheral sensory neuropathy, polyneuropathy, polyneuropathy chronic, sensory disturbance, sensory loss, and thermohypoesthesia. 'Neurologic consultations performed by neurologists following neurologic adverse event report or significant neurologic examination abnormalities detected by investigators.

Abbreviations: AE, adverse event; ITT, intent-to-treat; IV, intravenous; SAE, serious adverse event; SC, subcutaneous.

and six patients had treatment-induced ADA with low titers (4.62-8.18). The nine ADA-positive samples were analyzed in the NAb assay; five were negative for Nab, whereas four (from three patients) were confirmed Nab-positive with low titers (5.82-10.1). Individual profiles indicated no apparent alterations in tanezumab concentrations, efficacy, or incidence and severity of adverse events for the seven ADA-positive patients compared with patients who were ADA-negative.

\section{Study 1043}

A total of 678 patients were randomized and treated in Study 1043 (Figure 2B). Demographics and baseline characteristics were comparable across treatments; most ( $80 \%)$ patients received at least two of the seven planned tanezumab $\mathrm{SC}$ injections (Table 1). Mean treatment duration was similar across treatments (180.3-190.8 days).

\section{Efficacy}

Fewer than half of the patients in Study 1043 received more than two tanezumab treatments; therefore, efficacy results are presented only through week 16 . Tanezumab treatment resulted in improvements from baseline to week 16 in WOMAC Pain, WOMAC Physical Function, and PGA of OA scores (Figure 5A-C); similar improvements were seen 


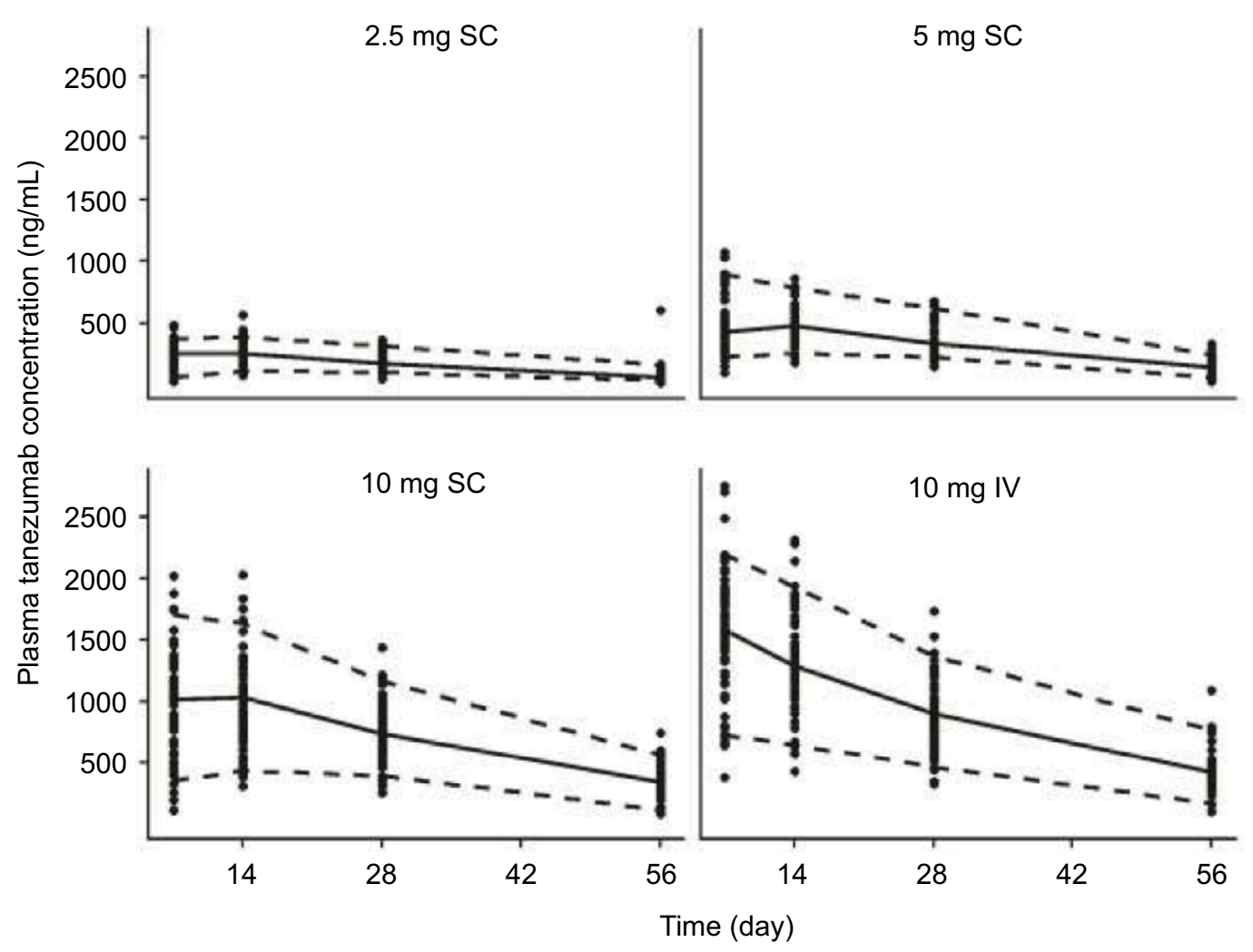

Figure 4 Study 1027:24 Individual observed (symbols) and predicted 5th (lower dashed black line), 50th (solid black line), and 90th (upper dashed black line) percentiles tanezumab concentrations over the first 8 weeks in patients who received a $2.5 \mathrm{mg} \mathrm{SC}, 5 \mathrm{mg} \mathrm{SC}, 10 \mathrm{mg}$ SC, or $10 \mathrm{mg}$ IV dose of tanezumab.

Abbreviations: IV, intravenous; SC, subcutaneous.

at week 8 . More patients treated with tanezumab 5 and 10 $\mathrm{mg}$ had $\geq 30 \%, \geq 50 \%, \geq 70 \%$, and $\geq 90 \%$ improvements in WOMAC Pain score than with tanezumab $2.5 \mathrm{mg}$; however, differences between tanezumab 10 and $5 \mathrm{mg}$ were minimal (Figure 5D). The percentage of OMERACT-OARSI responders was highest in patients treated with tanezumab $10 \mathrm{mg}$ (Figure 5E).

\section{Safety}

Adverse events in Study 1043 occurred at higher rates with tanezumab $10 \mathrm{mg}$ than with tanezumab 2.5 or $5 \mathrm{mg}$ (Table 2). The number of patients experiencing at least one serious adverse event was higher in the tanezumab $10 \mathrm{mg}$ group than in the tanezumab 2.5 or $5 \mathrm{mg}$ groups (Table 2). The most frequently investigator-reported serious adverse events were arthralgia $(\mathrm{n}=8 ; 4,1$, and 3 patients in the tanezumab 2.5 , 5 , and $10 \mathrm{mg}$ treatment groups, respectively), osteonecrosis $(\mathrm{n}=9 ; 1,4$, and 4 patients in the tanezumab 2.5, 5, and $10 \mathrm{mg}$ treatment groups, respectively), and worsening $\mathrm{OA}(\mathrm{n}=7 ; 2,1$, and 4 patients in the tanezumab $2.5,5$, and $10 \mathrm{mg}$ treatment groups, respectively). Discontinuation due to an adverse event was highest in the tanezumab $2.5 \mathrm{mg}$ group (Table 2).
Arthralgia was the most frequent reason for discontinuation (tanezumab $2.5 \mathrm{mg}, \mathrm{n}=2$ [0.9\%]; tanezumab $5 \mathrm{mg}, \mathrm{n}=2$ [0.9\%]; tanezumab $10 \mathrm{mg}, \mathrm{n}=1$ [0.4\%]). No deaths occurred.

Injection site reaction incidence was generally low $(\leq 9.5 \%$ in each group), although slightly higher than in Study 1027. The most frequent injection site reactions were ecchymosis and erythema. Most injection site reactions were mild, and none were severe.

Adverse events of abnormal peripheral sensation occurred at higher incidence in the tanezumab $10 \mathrm{mg}$ group (Table 2). Most adverse events of abnormal peripheral sensation resolved before last patient contact. Most $(\geq 81.7 \%)$ patients had no new or worsened abnormality at final neurologic examination (Table 2).

Nine patients (tanezumab $2.5 \mathrm{mg}, \mathrm{n}=1$ [0.4\%]; tanezumab $5 \mathrm{mg}, \mathrm{n}=4$ [1.8\%]; tanezumab $10 \mathrm{mg}, \mathrm{n}=4$ [1.8\%]) in Study 1043 had an adverse event initially reported as osteonecrosis (Figure 6) by the investigator. Eight of these patients had documented evidence of preexisting OA in the affected joint. Overall, 34 patients (tanezumab $2.5 \mathrm{mg}, \mathrm{n}=11$ [4.8\%]; tanezumab $5 \mathrm{mg}, \mathrm{n}=8$ [3.6\%]; tanezumab $10 \mathrm{mg}, \mathrm{n}=15$ [6.6\%]) reported TJR (all-cause). This included all nine patients with 
A

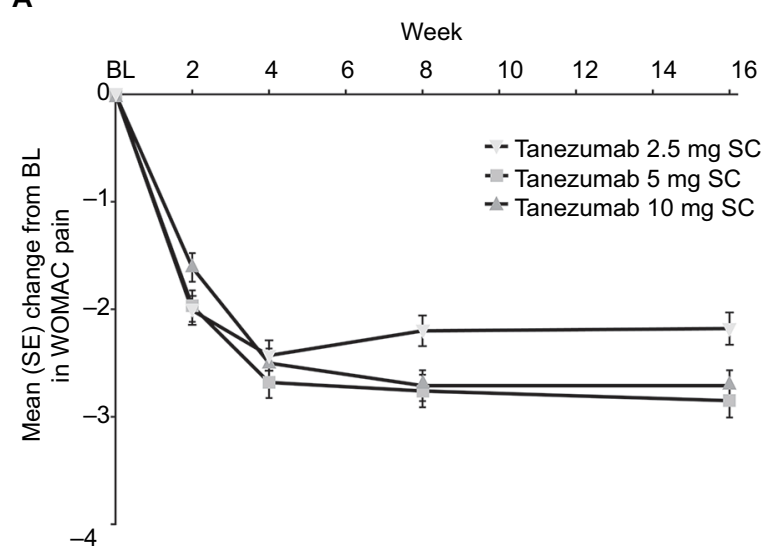

B

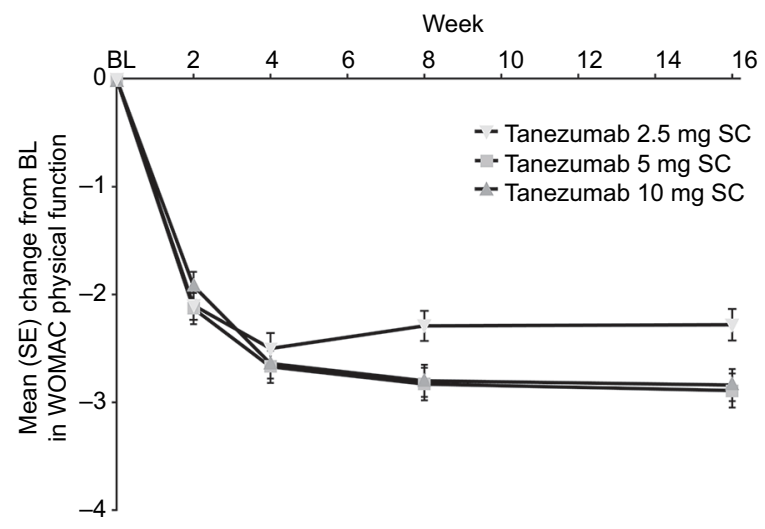

D

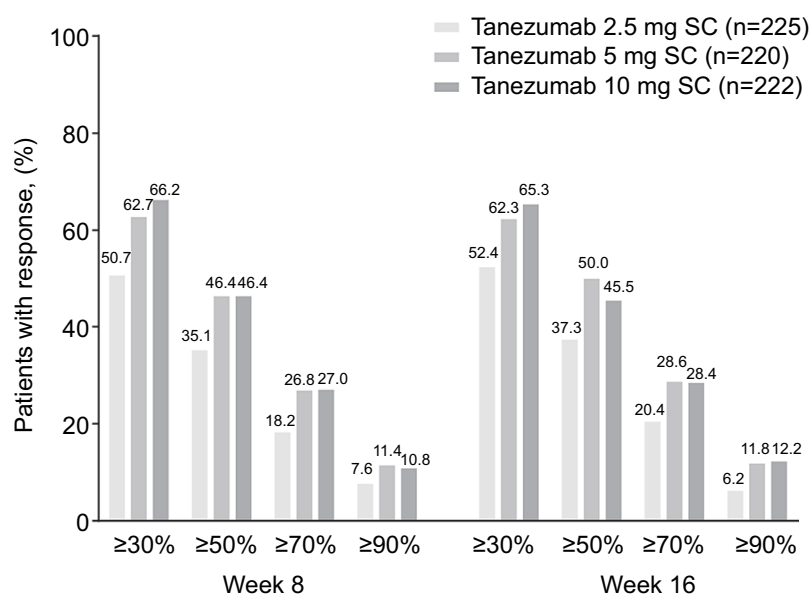

E

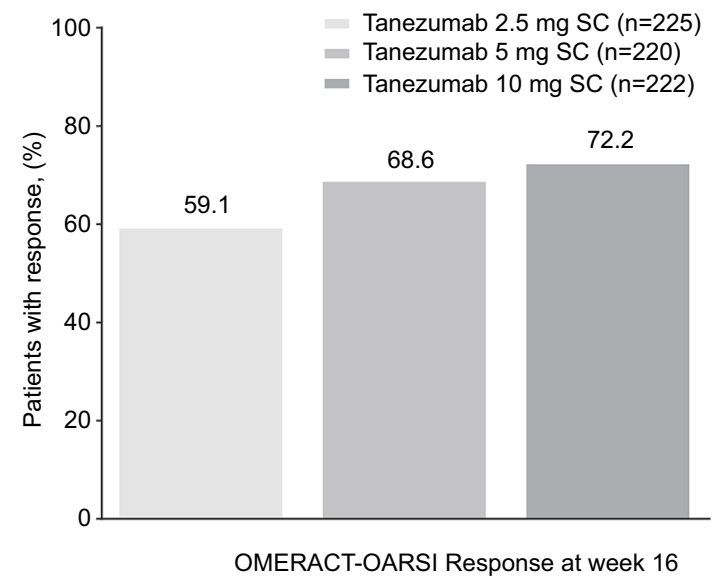

Figure 5 Study 1043:25 Mean (SE) change from baseline in (A) WOMAC Pain, (B) WOMAC Physical Function, and (C) PGA of OA; percentage of patients with (D) $\geq 30 \%$, $\geq 50 \%, \geq 70 \%$, and $\geq 90 \%$ reduction from baseline in WOMAC pain scores at weeks 8 and I6; and (E) OMERACT-OARSI response at week 16 (ITT, LOCF).

Abbreviations: BL, baseline; ITT, intent-to-treat; IV, intravenous; LOCF, last observation carried forward; OA, osteoarthritis; OMERACT-OARSI, Outcome Measures in Rheumatology Arthritis Clinical Trials-Osteoarthritis Research Society International; PGA, Patient's Global Assessment; SC, subcutaneous; SE, standard error; WOMAC, Western Ontario and McMaster Universities Osteoarthritis Index.

reported osteonecrosis plus an additional 25 patients. Of these 34 patients, 32 (94\%) took NSAIDs at some time while they were treated with tanezumab.
Twenty-two patients, including all nine patients with adverse events initially reported as osteonecrosis and 13 patients with all-cause TJR, in Study 1043 were reviewed by 


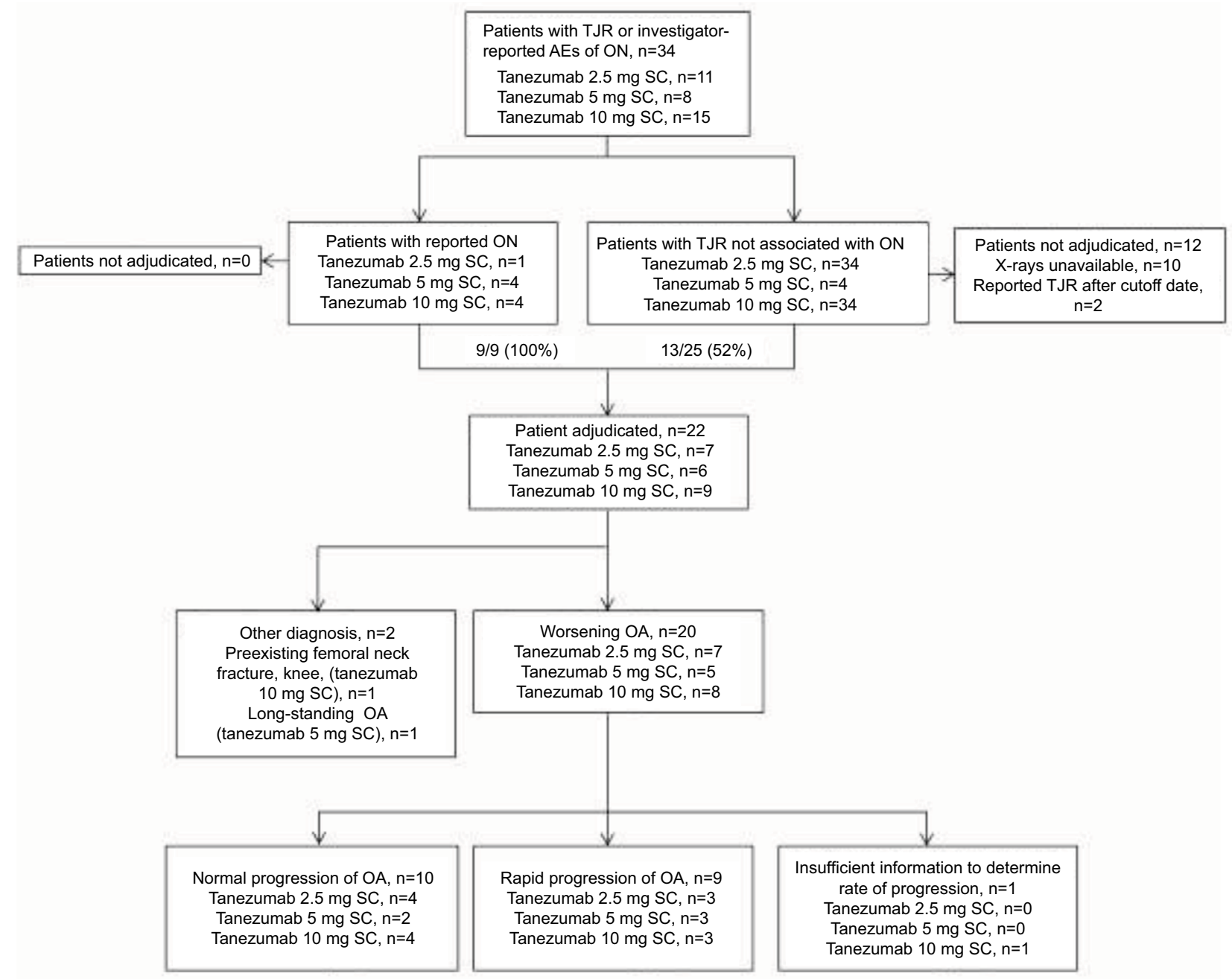

Figure 6 Study 1043:25 Adjudication outcomes of joint safety events.

Abbreviations: $\mathrm{AE}$, adverse event; OA, osteoarthritis; ON, osteonecrosis; SC, subcutaneous; TJR, total joint replacement.

adjudication committee. No patients were judged as having osteonecrosis. Twenty patients were adjudicated to worsening OA: 10 to normal progression of OA, nine to rapid progression of OA, and one as worsening OA (insufficient information to distinguish between rapid and normal progression; Figure 6). Two patients were adjudicated as another diagnosis (one with preexisting femoral neck fracture [tanezumab 10 $\mathrm{mg}$ ] and the other had long-standing OA [tanezumab $5 \mathrm{mg}$ ]). All nine patients adjudicated to rapid progression of OA reported concomitant NSAID use during the study.

Long-term SC tanezumab treatment was not associated with meaningful changes in clinical laboratory values, vital signs, or electrocardiographic results.

\section{Pharmacokinetics and anti-tanezumab antibodies}

The PK profile in Study 1043 was comparable to Study 1027 , as was the immunogenicity profile, with only $1.3 \%$ of patients testing positive for the presence of ADA across the three treatment groups. Of the 2021 serum samples tested (from 675 patients), 368 samples were presumptively ADApositive, of which 17 samples (from nine patients) were positive upon confirmatory assay. Of these, 15 samples (nine patients) had titer results $\geq 4.32(5.12-15.54)$. Three of the nine patients were baseline ADA-positive with no significant increase in titer postdose, while six patients had treatmentinduced ADA. Six of the 15 samples screened positive for $\mathrm{Nab}$, with five samples (from four patients) confirming positive with low titers (5.61-9.93). Individual profiles indicated no apparent differences in tanezumab concentrations, efficacy, or safety for the nine ADA-positive patients versus ADA-negative patients.

\section{Discussion}

Two studies were conducted to demonstrate the efficacy and safety of SC tanezumab in patients with moderate-tosevere OA pain. Study 1027 was also designed to evaluate 
therapeutic equivalence of SC and IV tanezumab $10 \mathrm{mg}$. Due to the partial clinical hold, enrollment in Study 1027 was insufficient to yield adequate power to fulfill the primary objectives, and no statistical hypothesis testing was performed. However, qualitative inspection of results at week 8 indicates tanezumab SC and IV were associated with improvements in pain, physical function, and global well-being compared with placebo.

Onset and duration of analgesia over the 8-week dosing interval with all SC doses of tanezumab in both studies were similar to the tanezumab $10 \mathrm{mg}$ IV dose in Study 1027. Moreover, the magnitude of response and analgesic profile observed with tanezumab $10 \mathrm{mg}$ IV was similar to previously published studies in patients with OA of the knee or hip in which the enrollment objectives were fully met. ${ }^{6-8}$ Thus, the efficacy profile of tanezumab SC appears similar to IV administration based on a qualitative comparison in Study 1027 and an indirect comparison to previously published results. ${ }^{6-13}$

In Study 1043, tanezumab 5 and $10 \mathrm{mg}$ resulted in similar improvements from baseline at weeks 8 and 16, and these improvements were larger than those in the tanezumab $2.5 \mathrm{mg}$ group. Benefit with tanezumab $10 \mathrm{mg}$ over $5 \mathrm{mg}$ was minimal. These results are also consistent with prior studies. ${ }^{6-13}$

SC tanezumab had a favorable safety profile in both the studies. Overall incidence and types of adverse events reported were generally comparable to IV administration in OA patients. ${ }^{6,7,9-13}$ Incidence of injection site reactions was generally low across both the studies, although slightly higher in Study 1043 due to longer study duration and additional dosing. A slightly higher incidence of injection site reactions was reported relative to other tanezumab studies conducted with IV administration only $^{6-13}$ - suggesting a difference in the profile between SC and IV administration - but may be due, at least in part, to the more detailed injection site assessment in those studies. Most injection site reactions in the current two studies were mild; none were severe. Across treatments, the incidence of serious adverse events and discontinuations due to adverse events were low. No events were adjudicated as primary osteonecrosis. The vast majority of patients had no significant abnormality on neurologic examination at their final assessment.

Overall, PK descriptive summaries and individual profiles of tanezumab suggest that absorption and disposition of SC tanezumab were similar across $2.5,5$, and $10 \mathrm{mg}$ doses and that exposure increases linearly with dose. As expected, the average tanezumab plasma concentrations in the first 4 weeks after dosing were slightly lower with $10 \mathrm{mg}$ SC than with $10 \mathrm{mg}$ IV administration, but (as PK/PD simulations suggested) did not decrease efficacy.
During the conduct of clinical OA pain studies of tanezumab and other NGF inhibitors, a signal event initially described by investigators as osteonecrosis often leading to TJR raised concerns about joint-related safety of tanezumab and led to a partial clinical hold on the entire NGF inhibitor class by the US FDA. Reports of osteonecrosis and all other TJRs underwent careful and thorough investigation by an independent expert adjudication committee. ${ }^{23}$ No evidence was found to indicate that tanezumab was associated with an increased risk of osteonecrosis, a disease process distinct from OA, although a risk of rapidly progressive OA was identified. ${ }^{16}$ In our studies, nine patients were adjudicated to rapid progression of OA; all had taken concomitant NSAIDs during the study. Thus, similar to other reported studies, ${ }^{11}$ the risk of rapidly progressive OA with tanezumab was greatest when coadministered with NSAIDs.

The incidence of anti-tanezumab antibodies was low. Based on ADA incidence in IV studies, the SC route is not more immunogenic than IV infusion. Individual patient profiles indicated no apparent alterations in tanezumab concentrations, efficacy, or incidence and severity of adverse events in patients who were ADA-positive compared with patients negative for ADA.

A significant limitation of these studies was the impact of the clinical hold on the duration and enrollment of both the studies, resulting in the insufficiency to yield adequate statistical power to fulfill the primary objectives in Study 1027 and a reduction in the number of tanezumab doses administered in Study 1043.

\section{Conclusion}

Although these studies were limited by the partial clinical hold, the data provide preliminary evidence that the efficacy and safety of SC tanezumab is generally similar to IV administration in patients with OA pain.

\section{Acknowledgments}

These studies were funded by Pfizer Inc. The authors gratefully acknowledge Rujia Xie for her work on predictive modeling of tanezumab SC efficacy. Editorial support was provided by Joseph Oleynek from Engage Scientific Solutions, and this work was funded by Eli Lilly and Pfizer Inc.

\section{Disclosure}

Charles Birbara has received no financial support of any kind from any pharmaceutical company except for work involved in conducting a clinical trial, and is a member of a speakers' bureau for Forest Laboratories Inc., GlaxoSmithKline, and Roche. Robert J Fountaine, Mark T Brown, Christine 
R West, Rosalin H Arends, Aimee M Burr, and Kenneth M Verburg are employees of and hold stock or stock options in Pfizer Inc. Michael D Smith was an employee of Pfizer Inc. at the time of these studies and holds stock or stock options in Pfizer Inc. His current affiliation is Astellas Inc. Eugene J Dabezies JR reports no conflicts of interest in this work.

\section{References}

1. Mantyh PW, Koltzenburg M, Mendell LM, Tive L, Shelton DL. Antagonism of nerve growth factor-TrkA signaling and the relief of pain. Anesthesiology. 2011;115(1):189-204.

2. Hefti FF, Rosenthal A, Walicke PA, et al. Novel class of pain drugs based on antagonism of NGF. Trends Pharmacol Sci. 2006;27(2):85-91.

3. Walsh DA, McWilliams DF, Turley MJ, et al. Angiogenesis and nerve growth factor at the osteochondral junction in rheumatoid arthritis and osteoarthritis. Rheumatology (Oxford). 2010;49(10):1852-1861.

4. Watson JJ, Allen SJ, Dawbarn D. Targeting nerve growth factor in pain: what is the therapeutic potential? BioDrugs. 2008;22(6):349-359.

5. Abdiche YN, Malashock DS, Pons J. Probing the binding mechanism and affinity of tanezumab, a recombinant humanized anti-NGF monoclonal antibody, using a repertoire of biosensors. Protein Sci. 2008;17(8):1326-1335.

6. Brown MT, Murphy FT, Radin DM, Davignon I, Smith MD, West CR. Tanezumab reduces osteoarthritic knee pain: results of a randomized, double-blind, placebo-controlled phase III trial. J Pain. 2012; 13(8):790-798.

7. Brown MT, Murphy FT, Radin DM, Davignon I, Smith MD, West CR. Tanezumab reduces osteoarthritic hip pain: results of a randomized, double-blind, placebo-controlled phase III trial. Arthritis Rheum. 2013;65(7):1795-1803.

8. Ekman EF, Gimbel JS, Bello AE, et al. Efficacy and safety of intravenous tanezumab for the symptomatic treatment of osteoarthritis: 2 randomized controlled trials versus naproxen. J Rheumatol. 2014; 41(11):2249-2259.

9. Lane NE, Schnitzer TJ, Birbara CA, et al. Tanezumab for the treatment of pain from osteoarthritis of the knee. N Engl J Med. 2010;363: 1521-1531.

10. Nagashima H, Suzuki M, Araki S, Yamabe T, Muto C; Tanezumab Investigators. Preliminary assessment of the safety and efficacy of tanezumab in Japanese patients with moderate to severe osteoarthritis of the knee: a randomized, double-blind, dose-escalation, placebo-controlled study. Osteoarthritis Cartilage. 2011;19(12):1405-1412.

11. Schnitzer TJ, Ekman EF, Spierings EL, et al. Efficacy and safety of tanezumab monotherapy or combined with non-steroidal anti-inflammatory drugs in the treatment of knee or hip osteoarthritis pain. Ann Rheum Dis. 2015;74(6):1202-1211.

12. Schnitzer TJ, Lane NE, Birbara C, Smith MD, Simpson SL, Brown MT. Long-term open-label study of tanezumab for moderate to severe osteoarthritic knee pain. Osteoarthritis Cartilage. 2011;19(6): 639-646.
13. Spierings EL, Fidelholtz J, Wolfram G, Smith MD, Brown MT, West CR. A phase III placebo- and oxycodone-controlled study of tanezumab in adults with osteoarthritis pain of the hip or knee. Pain. 2013;154(9): 1603-1612.

14. Lalovic B, Xie R, Marshall S, Arends R. Population PK analysis of tanezumab administered to healthy volunteers subcutaneously or intravenously. Poster presented at: American Society for Clinical Pharmacology and Therapeutics (ASCPT); March 17-20, 2010; Atlanta, GA.

15. Xie R, Arends R, Olson S, Marshall S. Preliminary pharmacokinetic/ pharmacodynamic (PK/PD) analysis for the effect of tanezumab on overall daily pain score data in adults with moderate-to-severe pain due to osteoarthritis of the knee. Poster presented at: Population Approach Group in Europe (PAGE); June 23-26, 2009; St Petersburg, Russia.

16. Pfizer Inc. [home page on the Internet]. Tanezumab Arthritis Advisory Committee briefing document. New York, NY: Pfizer Inc.; 2012 [updated February 8, 2012]. Available from: http://www.fda.gov/downloads/ AdvisoryCommittees/CommitteesMeetingMaterials/Drugs/ArthritisDrugsAdvisoryCommittee/UCM295205.pdf. Accessed February 2, 2017.

17. Altman R, Alarcón G, Appelrouth D, et al. The American College of Rheumatology criteria for the classification and reporting of osteoarthritis of the hip. Arthritis Rheum. 1991;34(5):505-514.

18. Altman R, Asch E, Bloch D, et al. Development of criteria for the classification and reporting of osteoarthritis. Classification of osteoarthritis of the knee. Diagnostic and Therapeutic Criteria Committee of the American Rheumatism Association. Arthritis Rheum. 1986;29(8): 1039-1049.

19. Kellgren JH, Lawrence JS. Radiological assessment of osteo-arthrosis. Ann Rheum Dis. 1957;16(4):494-502.

20. Bellamy N, Buchanan WW, Goldsmith CH, Campbell J, Stitt LW. Validation study of WOMAC: a health status instrument for measuring clinically important patient relevant outcomes to antirheumatic drug therapy in patients with osteoarthritis of the hip or knee. J Rheumatol. 1988;15(12):1833-1840.

21. Stengaard-Pedersen K, Ekesbo R, Karvonen AL, Lyster M. Celecoxib $200 \mathrm{mg}$ q.d. is efficacious in the management of osteoarthritis of the knee or hip regardless of the time of dosing. Rheumatology (Oxford). 2004;43(5):592-595.

22. Pham T, van der Heijde D, Altman RD, et al. OMERACT-OARSI initiative: Osteoarthritis Research Society International set of responder criteria for osteoarthritis clinical trials revisited. Osteoarthritis Cartilage. 2004;12(5):389-399.

23. Hochberg MC. Serious joint-related adverse events in randomized controlled trials of anti-nerve growth factor monoclonal antibodies. Osteoarthritis Cartilage. 2015;23(Supp1 1):S18-S21.

24. Pfizer. Efficacy And Safety Study OfTanezumab Subcutaneous Administration In Osteoarthritis - A Subcutaneous/Intravenous Bridging Study. Available from: https://clinicaltrials.gov/ct2/show/NCT01089725. NLM identifier NCT01089725. Accessed September 28, 2017.

25. Pfizer. A Long Term Study of the Safety of Tanezumab When Administered By Subcutaneous Injections. Available from: https://clinicaltrials. gov/ct2/show/NCT00994890. NLM identifier NCT00994890. Accessed September 28, 2017.
Journal of Pain Research

\section{Publish your work in this journal}

The Journal of Pain Research is an international, peer reviewed, open access, online journal that welcomes laboratory and clinical findings in the fields of pain research and the prevention and management of pain. Original research, reviews, symposium reports, hypothesis formation and commentaries are all considered for publication.

\section{Dovepress}

The manuscript management system is completely online and includes a very quick and fair peer-review system, which is all easy to use. Visit http://www.dovepress.com/testimonials.php to read real quotes from published authors. 